\title{
Autosomal dominant Charcot-Marie- Tooth disease type 2 due to TFG mutation
}

INSERM

\section{Source}

INSERM. (1999). Orphanet: an online rare disease and orphan drug data base. Autosomal dominant Charcot-Marie-Tooth disease type 2 due to TFG mutation. ORPHA:435819

A rare, axonal hereditary motor and sensory neuropathy characterized by adult onset of slowly progressive distal muscle weakness and atrophy, decreased deep tendon reflexes of lower limbs, and mild distal sensory loss leading to gait difficulties in most patients. 